\title{
Scientific writing: the process and the pitfalls
}

\author{
Roger W. Byard
}

Accepted: 23 June 2013/Published online: 6 July 2013

(C) Springer Science+Business Media New York 2013

The recent release of updated journal impact factors has shown that Forensic Science Medicine and Pathology has risen from its first entry of 0.698 in 2010, to 1.44 in 2011, and now to a respectable 2.438 in 2012. This is a very gratifying trend and is a tribute to the high quality submissions from our authors and the excellent work of our reviewers, editorial staff, and colleagues at Springer publishers. However, impact factors can also decline and so it is essential that the quality and progress of our journal is maintained so that this level of excellence will only further increase in subsequent years.

For this reason it is timely to examine aspects of scientific writing and the problems that authors may encounter. Unfortunately research may have diminished significance if the results of studies and observations are not reported to the wider professional community within a reasonable time. Prompt dissemination enables data to be evaluated and further developed. Much of the success of this process depends upon researchers and pathologists being able to write about their work clearly, in a manner that is suitable for publication, and that is accessible to their colleagues.

Writing well is not always as easy as it sounds, and although researchers may be highly skilled at generating and collecting data, the ability to put together a wellcrafted paper may be less well developed. A major problem in submissions which either require significant revision or are rejected outright is a lack of critical examination and explanation of results [1]. The most

\section{R. W. Byard $(\square)$}

Discipline of Anatomy and Pathology, School of Medical Sciences, The University of Adelaide, Level 3 Medical School North Building, Frome Road, Adelaide, SA 5005, Australia e-mail: roger.byard@sa.gov.au disappointing papers are those where it appears that a considerable amount of work has been expended by researchers who have then failed to formulate credible or logical conclusions. Often there appears to be a lack of understanding of the precise focus of the paper; specifically, the hypothesis being tested, and how the results either support or refute it. A good way of approaching a study is to encapsulate the aim within the title and to keep coming back to this; i.e., to not stray from the essential path of the paper. In-house peer review by colleagues prior to submission may also be helpful to authors, but this must involve a genuine assessment of the paper and not just a cursory overview-something that will take time to do if it is undertaken properly.

The discipline imposed by some journals of limiting the word count for Abstracts provides an example of how writing within certain constraints forces an author to focus on the most significant aspects of his or her research. Other journals may have boxes that contain what is known about the topic and what this paper adds to the literature. As another example of this process, Forensic Science Medicine and Pathology encourages this by requiring four to five "Key Points" that clearly and succinctly summarize the major features of each paper. It is, however, disappointing to see how many authors do not provide this information on their first submission.

Cultural differences in expression and the use of the vernacular, combined with problems in translation, can often seriously reduce the impact of a paper. For authors whose first language is not that of the journal, the use of language service companies may be one way of getting appropriate editing so that potentially confusing idiosyncratic expressions and grammatical errors will be removed from the text prior to submission. English language services are available for Forensic Medicine Science and 
Pathology through Springer Publishers, and contributors are certainly encouraged to make use of them.

Selection of an appropriate journal for submission is important. Examination of recent issues of the journal being considered will give authors a good idea of the types of papers that are being accepted, the correct format and the editorial focus. Failure to follow "Instructions to Authors" may delay processing, as authors will be required to correct multiple minor errors. In fairness to authors, the fact that every journal has its own, sometimes idiosyncratic, requirements does not make the process any easier; however the submission of a paper that has been clearly formatted for another journal, tends to suggest that the authors are "journal shopping" rather than attempting to correct fundamental flaws in their work.

Selecting journals that have rapid review times and that publish high quality papers quickly is one way of ensuring that work is made available promptly. Forensic Science Medicine and Pathology has always striven to have rapid processing times with the aim of several days for the internal review, 3 weeks for the external review, and around 4-5 weeks for electronic publishing with on-line access after acceptance.
Writing a scientific paper is not an easy process, and it is also not one that comes to everyone naturally. The question then is "how does one approach it?". Reading papers in respected journals, and examining their organization, style, and presentation, is a good place to start-then write. Two quotes from Epictetus and William Hazlett, respectively (two authors who between them cover many centuries of writing) emphasize this process: "if you wish to be a writer, write" and "the more a man [sic] writes, the more he can write" [2, 3]. In other words, the best way to develop expertise in writing scientific works is to continually practice writing concise and focused papers. As with most activities, success is usually directly proportional to the amount of time, effort, and attention that have been devoted to it.

\section{References}

1. Home PD. Techniques for ensuring that your next paper is quite unsuitable for publication. J R Coll Phys Lond. 1988;22:48-50.

2. http://quotationsbook.com/quote/42661/. Accessed 21 July 2013.

3. http://www.writersservices.com/mag/m_quotes_writers.htm. Accessed 21 July 2013. 